\title{
Drug Taking and Employment: Exploring the Employable Citizen in UK Policy
}

\begin{abstract}
This article extends contemporary debates surrounding drug taking and employment through exploring the importance of economic participation in UK anti-drug policy. Specifically, we undertake a critical discourse analysis (CDA) of recent drug taking policy documents to demonstrate how key ideological repertoires position drug consumption as the antithesis of economic potential and the productive subject. Engaging with recent critiques of neoliberalism, we develop the concept of the 'employable citizen' to (i) capture the increasing regulation of working identities deemed viable or appropriate, and (ii) foreground the connections between the contrasting spaces of drug taking and employment. After analysing the taxonomies that connect drug taking and the employable citizen, we discuss how our findings inform the broader regulation of drug-taking policy. We then conclude by examining the implications of the employable citizen as an ideological position and its consequences in terms of influencing policy and organizational discussions surrounding drug taking and employment.
\end{abstract}

\section{Keywords}

Drug taking and employment, employability, neoliberalism, public policy, work and citizenship.

\section{Contact Information}

Charlotte Smith, The York Management School, University of York, Freboys Lane, Heslington, York, UK, YO10 5GB. Email: charlotte.smith@york.ac.uk, Tel: +44 (0)1904 325031. 


\section{Introduction}

This article advances recent debates surrounding drug taking through exploring the role of economic life as a key construct informing UK drug policy. While studies of drug taking and drug behaviours have highlighted the social parameters which shape norms surrounding consumption (Parker et al., 2011), we argue that the increasing dominance of neoliberal expectations of productive selves informs the new moral economy of drug taking. This in turn discursively shapes what it means to be an economically productive citizen. To articulate this, we introduce the concept of the 'employable citizen', invoking recent workability policies surrounding the individualisation of health and wellbeing. Through an analysis of UK drug-taking policy and practice, we identify key ideological repertoires that restrict the possibility of being both a drug taker and an economically productive citizen. In connecting these repertoires to recent organisational employee governance practices, we suggest that such discursive strategies legitimise organisational intervention surrounding employee monitoring.

Public accounts of drugs are typically characterised by narratives of fear, threat and menace and are very similar to the marginalisation of other lifestyle behaviours that are positioned as deviant (Goode and Ben-Yehuda, 2009). This is in part driven by an assumption that drug taking is antithetical to full participation in economic life (Brewis et al., 2006). However, as Blackman (2004: 47-52) suggests, there has been an enduring and intimate relationship between drugs and economic spaces. Sociological studies since the 1950s have demonstrated the importance of understanding drug taking as, for example, a form of resistance or political act that constitutes part of a complex milieu of sub-cultural activities (e.g. Becker, 1953). Some of these sentiments are echoed in more recent research exploring the normalisation of drug taking as part of recreational pursuits defined by opportunities of 
choice and enjoyment (Blackman, 2004; 2007; Sanders, 2005). This has invariably led to an intertwining of drug taking with commercial enterprises surrounding music, as shown in Collins' (1997) study of ecstasy cultures in the 1990s, or accounts of drugs enhancing the artistic potential of creative workers and writers (Plant, 1999), although as Haines-Saah (2014) notes, drug use acceptability often rests on a position of elite privilege. On the other hand, as Pennay and Moore (2010: 563) argue 'illicit drugs are widely seen as incompatible with rationality and discipline and are linked with loss of identity and agency...the 'addict', is a threat to the modern neo-liberal ideology of autonomy and freedom'. Likewise, we argue that both policy and practice sequester spaces for consumption through discourses that manifest in formal texts discussing the consumption of drugs. Within these political movements we see an emphasis on control of the self in ways that form part of a broader 'social surge of individualisation' (Beck, 1992: 87).

In this article we suggest that the positions found within contemporary narratives surrounding drug taking are part of a broader ideological process through which drug takers are discursively positioned as economically impotent. Central to this is the position of 'work' as producing or sustaining a socially and economically productive citizen. In the past 20 years, the moral economies of work have been accorded greater purchase, for example, in larger debates surrounding labour participation and health. Welfare programmes are underwritten by an assumption that work not only provides an individual with independence and autonomy over their lives, but also carries other benefits relating to well-being, albeit conditional on particular circumstances (see Nordenmark and Strandh, 1999). Subsequently, terms such as 'worklessness', 'workability' and 'employability' have become key constructs in welfare programmes, with the link between work participation and health now a political truism. Extending this, we draw on critical discourse analysis (CDA) to suggest that drugtaking policy texts reproduce and inform the concept of the employable citizen - a position 
that simultaneously (i) empirically promotes the image of an employee as drug-free and therefore fully 'employable' through their ability to be employed; and (ii) limits individual lifestyle possibilities by defining what characteristics and behaviours are legitimate, acceptable and can be upheld alongside the position of an economically productive citizen.

Our paper is organised as follows. First we present the critique of neoliberal technologies and their influence on drug-taking policy and social narratives. We then introduce the concept of the employable citizen as a means of connecting drug taking with

the recent debates surrounding contemporary employment, subsequently focussing on the regulation of employees. After introducing our empirical study, we focus on three strategies that demonstrate how the invocation of work simultaneously promotes the regulation of substance abuse and shuts down space for a viable subject position that can successfully combine working and substance use. We conclude by situating our debate in the larger context of drug taking and work, outlining the social, political and occupational consequences emerging from our analysis.

\section{The Neoliberalisation of Drug Taking}

Of the many social issues digested in policy and public narratives over the last century, the consumption of mind-altering substances has perhaps been the most enduring. Formal modes of prohibition in the UK extend back to 1914 banning the possession, distribution and sale of cocaine and opium (Home Office, 1914). While subsequent governments have varied in their degree of regulation, the UK presents an expedient setting to explore the construction of work in relation to drug taking given its continual reclassification and criminalisation of illegal substances. Much of this has been strongly influenced by a neoliberal agenda (Blackman, 2004: 124; Pryce, 2012: 45), as seen in recent calls for the reclassification of Ketamine from a Class $\mathrm{C}$ to a Class B drug (ACMD, 2013). This position is in stark contrast to accounts of 
drug taking as a socially situated cultural phenomenon and the drug taker as a viable member of society. As Parker et al. (2011; 2002: 960) suggest, 'most users of illicit drugs are primarily educated, employed young citizens with otherwise conforming profiles'. However, the ability to provide a more nuanced account of drug taking within political or social spheres is limited though a normative simplification that attributes individual behaviour to hedonistic or problematic consumption and ignores the diversity of people's drug consumption choices (Bancroft, 2009; Blackman, 2004; Shiner and Newburn, 1997).

There has been a suggestion that performance-enhancing drugs are moving beyond physical professions such as sport (Waddington and Smith, 2009) and into workplaces to support intense working practices, such as pilots using amphetamines or students taking prescription drugs to reduce fatigue (Greely et al., 2008; Plant, 1999: 115). Despite this, the prohibitive response to drug taking in organisational policies has been unrelenting. In the UK, $40 \%$ of organisations had a drug policy at the beginning of the 21 st century (CMI, 2003) with nearly one third of companies' drug and alcohol testing their staff (IIDTW, 2004). Much of the pro-testing literature draws on business-case debates highlighting the risks to corporate reputation through negative publicity, damage to the brand and impact on attracting future employees or investors (CMI, 2002; HSE, 2007). Other accounts suggest a more direct effect on economic productivity through increased absenteeism, poor time keeping, deteriorated relationships between colleagues, lower staff morale, employee theft, increased errors and accidents, workplace bullying, escalated stress levels, workplace violence and higher staff turnover (CMI, 2003; HSE, 2004; Johnson, 2007). Subsequently, organisational responses draw on neoliberal rationalities of harm reduction to legitimise surveillance practices such as employee testing (Ball, 2010). Yet the prohibitive drug stance by organisations may also be a scapegoating device that allows organisations to symbolically protect a moral order surrounding employee regulation in the labour process without clear evidence that drug takers 
are by this virtue not economically productive (Brewis et al., 2006). In other words, the moral economies and regulatory technologies surrounding labour and leisure may be more intimately connected within the production of anti-drugs discourses than first thought.

\section{The Employable Citizen}

Traditionally, the puritanical and protestant work ethic has highlighted that the importance and value of 'work' extends beyond an exclusive focus on economic output (Weber, [1930] 2001). Historical portrayals of the labouring but civilised individual as embodying the virtues of honest toil creates new motives for diligence, often accompanied by religious doctrines suggesting, 'the greatest to live have been ... honoured while in the pursuit of humble trades' (Magoon, 1849: 346). By comparison, those who failed to uphold these behaviours were morally derided, as suggested in O'Malley and Valverde's (2004: 31, emphasis added) account of the gin lanes of $18^{\text {th }}$ century London where 'for the undisciplined, unproductive and dangerous classes associated with the consumption of gin, there was reversion to the state of beastliness'.

However, during the past 20 years, the framing of paid work within particular moral economies has led to economic activity being increasingly conflated with one's value as a neoliberal citizen. Whilst much debate exists around the concept and consequences of 'citizenship', these emphasise the relational dynamics between the citizen and the state (Clarke et al., 2014) and individuals' inclusiveness and participation in public life (Hurenkamp et al., 2012). In particular, the inclusionary process of reallocating public resources is increasingly established on the creation and reproduction of subject positions that benefit and exclude particular groups, and yet are legitimised through a projected image of solidarity (Turner, 2001). Increasingly, the importance of an economically productive citizen - someone who is able to provide positive economic gains to society and who does not 
require the state for 'support' is situated within the wider political framework that places all social aspects, including health, culture, and well-being as primarily informed and assessed in economic terms (Fujiwara and Campbell, 2011). Within this process, political action not only influences but also is influenced by codes of civic order (Stevenson, 2014). Consecutive New Labour and Conservative governments in the UK have encouraged a flow of ideological ascriptions surrounding autonomy and self-responsibility, witnessed through the shift from welfare regimes towards an impetus on individualised responsibility and accountability in health and work (e.g. HM Government, 2010). In particular, un/employment is increasingly framed as an individual choice, redefining 'unemployment as a personal effect of the unemployed, who is incapable (or unwilling at the prevailing wage rate) to avail him - or herself of the opportunities in the labour market' (Overbeek, 2003: 17). Employability within this neoliberal agenda thus becomes a matter of individuals fitting and adjusting to labour market demands (Brown and Hesketh, 2004: 24; Gazier, 1999: 37-71). Subsequently, employability policies encourage individuals to perceive themselves as active subjects; responsible agents obliged to exercise autonomous choices for their own well-being, selfactualisation and self-fulfilment (Larner, 2000; Rose, 2000). A key part of this autonomy is 'choosing' to be what we term here an 'employable citizen' within the parameters reproduced through contemporary discourses of citizenship and labour.

In the production of the employable citizen, we propose that alternative subject positions are denied recognition: notably for our purposes, those who engage in any form of substance use. Subsequently, it is prudent to interrogate the spaces in which the simultaneous production of these desirable and undesirable subject positions takes place, exploring how the employable citizen is created, reproduced and subsequently influences discourses surrounding drug use. While neoliberal projections of a 'productive' subject are increasingly influential in all social and political spheres, we argue that a more nuanced concept of the 
employable citizen illuminates the intimate connections between drug taking and employment. Specifically, this term captures the dialogue between two trends now commonplace in accounts of contemporary work.

The first set of ideas informing the employable citizen relates to the possibilities of creating or expressing selfhood through economic participation. Increasingly, organisational participation has become a primary means of defining selfhood, with organisational cultures creating moral frameworks that employees both work and live by. As Fleming and Sturdy (2009: 570) note, this produces paradoxical leitmotifs where individuals are told to 'just be themselves' in work while being subject to increasing surveillance practices and cultural management techniques that promote characteristics or behaviours that can be commoditised by the organisation. Consequently, we witness a tapering of behaviours, attitudes or outlooks that legitimately 'belong' within organisational arenas.

Second, at a policy level, the employable citizen echoes the dominance of the 'workability' agenda, a concept emerging in the late 1980's from an index measuring work potential in terms of the health resources that an individual possesses (Tuomi et al., 1998). Workability now forms a key discourse in activation policies in Europe that require both benefit recipients to demonstrate they are actively seeking work (DWP, 2010), and local governments to show they are enabling individuals to become proactive and independent workers (Workability Europe, 2012). Workability thus forms part of a larger discourse that enables a move from biomedical indicators of health towards a broader more subjective concept of well-being (Robertson and Cooper, 2011: 78-90). However, workability's popularity in policy and practice may not solely be attributed to its rigour, but its endorsement of neoliberal ascriptions of the economically productive citizen. For example, its focus on individual, rather than job related, measures (such as the number of diagnosed conditions, mental resources, sick leave and own assessment of workability) echoes the 
significant shift towards viewing the individual themselves (rather than structures or socioeconomic conditions) as the main barrier to employment. To be 'employ-able' is therefore encapsulating the individualised assumption that those who do not work do so by personal choice or virtue.

However, as yet we know little of how one set of neoliberal-infused discourses surrounding economic participation closes down viable subject positions surrounding other social phenomena, such as substance use. Using our concept of the employable citizen, we analyse drug-taking public policy and practitioner texts to explore how the deployment of particular ideals surrounding economic life inform inter alia positions on substance use.

\section{Research Methods}

Our research draws on fourteen key UK political texts that focus on substance use from 1995 (when the first UK drugs strategy was published) to 2012 (see Table 1). This timeframe is notable, not only through capturing the UK's drug policy shift to a particular form of rationality specific to neo-liberalism in the late 1980s (Bunton, 2001) but also following what Fleming and Sturdy (2009) suggest is a revolutionary period in which working practices have become more culture-intensive and 'boundaryless'. At the same time, a rise in discussions surrounding work as bringing health and well-being benefits emerged as a key tenet of the New Labour (1997) government, although incidences of work-related stress and occupational injury rose from 200,000 self-reported cases in 1990 to 425,000 cases in 2005 (HSE, 2006). Despite a shift to criminalisation in UK drug policy, there has also been a focus on 'helping users to help themselves', reproducing neoliberal technologies (Seddon, 2006: 691-692).

In light of our focus on work-related subject positions, we understood the term 'political text' holistically, arguing that analysis must include documents of a legal authority as well as those produced by bodies with significant influence in work-related arenas. These 
latter sources were composed of key texts from the Chartered Instituted of Personnel and Development (CIPD) and the Chartered Management Institute (CMI); two influential bodies that promote organisational 'cultures of practice' within the neoliberal agenda (Walker, 2011). To ensure a systematic process of inclusion and exclusion, we applied three criteria. First, all texts were produced by a UK body to minimise the complexity brought by different national legislative contexts. Second, all texts were either part of a government strategy or cited by other texts included in our corpus, as testament to their significance in drug debates. Finally, all texts were either publicly accessible or available to members of a recognised professional body. While we concede that our criteria may exclude discussion of marginal forms of employment due to the 'professional' focus of some of our texts, following these measures, our corpus of texts resulted in over five hundred pages of A4 typeset text.

\section{INSERT TABLE 1 HERE}

To mobilise our thesis, we adopted a Critical Discourse Analysis (CDA) approach, understanding public texts as active vehicles that articulate legitimate forms of power and knowledge and produce new possibilities for legitimacy and regulation. While political resources feed directly into other social spaces, these spaces often manifest in subtle ways, such as ideas surrounding professionalisation and managerial best practice. We began with a thematic analysis to identify the key terms and ideas used to operationalise the discussion of drug taking, and how each of these terms was either defined or related to other key terms. While a range of themes conducive to neoliberal productions of the autonomous subject emerged across the corpus, such as 'well-being', 'harm', 'working together', and 'communities' (see Bunton, 2001; McGregor, 2001), many references to the economic sphere were also found in all the texts consulted. This formed the basis of a textual analysis that 
identified relationships between various concepts, how positions were developed and the ascribed valuation of particular ideas (Wodak et al., 2009). For example, techniques identified what was omitted or silenced in the texts. This included strategies of differentiation and distinction (between drug takers and non-drug takers, for example), and identified exceptions outside the scope of claims made within and across the texts, particularly surrounding explanations of drug taking. This informed a closer analysis of how the multiple voices, subjects and concepts were produced, called upon, woven in, related to each other and recontextualised in the corpus to produce particular subject positions (Candlin and Maley, 1997). In presenting a synthesis of this account below we have carefully selected excerpts that are emblematic of the larger corpus.

\section{Producing the Employable Citizen}

In this section, we examine how the employable citizen was produced in correlation with anti-drug narratives. Our analysis revealed a dominant theme: that drugs - and by affiliation, drug users - were anathematic of a healthy and productive workforce, whether individuals were located inside or outside the workforce. This required the creation of narrow categories to define both cost and value economically. For example the Home Office (2002) strategy rests its subsequent strategy on quantified statements of a negative economic effect of drug use:

Drug use gives rise to between 10 billion and 18 billion a year in social and economic costs (Home Office, 2002: 6).

Similarly, Business Link focuses on employers' responsibilities towards substance use through correlating drug-related behaviour and productivity: 
Disruption [from smoking, drugs, and alcohol] can occur in terms of lost productivity (Business Link, 2011: 1).

This connection could be traced back to the 1995 government drug strategy which suggests that:

The direct cost of tackling drug misuse is also borne by many private organizations such as businesses, charities, and the voluntary sector generally (Home Office, 1995: $51)$.

This was not only achieved through isolating the drug taker as miscreant but simultaneously connected to concepts surrounding labour participation, economic value through paid employment, and the importance of intervention through the creation of the 'employable citizen': an individual who wanted to participate in employment. To detangle this relationship between economic participation and drug prohibition further, we now focus on three strategies that called on and reproduced the employable citizen as a key actor in the production of drugs policy.

\section{The Honour of the Employable Citizen}

In light of recent commentaries surrounding drug taking (e.g. Nutt et al., 2009), the prohibitive undercurrent of policies was unsurprising. Yet to create the employable citizen required more than a nihilistic rejection of drug taking; instead there was evidence of a sustained and totalising rejection of the individual drug taker as anything other than an 'othered' subject. This was achieved using two techniques. The first was referring to 'use' and 'misuse' consecutively. For example, the 2008 drug strategy made a number of 
statements surrounding the damaging effects of drugs including 'drug misuse can damage an individual's ability to work' (Home Office, 2008: 21), and 'drug use also limits the ability to work' (Home Office, 2008: 27). This conflates the 'use' of any drugs beyond bounded medical parameters as damaging or detrimental since 'all controlled drugs are harmful' (Home Office, 2002: 3). The only delineation was through drawing on medical distinctions to support statements of 'harm':

The non-medical use of drugs that are only intended for use in medical treatment and the use of drugs that have no accepted medical purpose (Home Office, 1995: 35).

The conflation between use and misuse also allowed statements not grounded in scientific fact or evidence (usually required in policy documents as a form of legitimisation) to be upheld through appealing to a moral imperative. 'Social problems' as a genre carry high purchase due to their attachment to multiple eventualities, creating a distinct connection between drug taking, youth, crime and the working class (Foster, 2000; Jeffs, 1997). For example, behaviours are situated as 'good', 'bad', 'right', 'wrong', 'healthy' or 'dangerous' (Roth, 2010) and therefore legitimise actions to mediate their impact. Further, Skeggs and Loveday (2012) suggest discourses associated with the 'underclass' are directly connected to particular activities through being mobilised via narratives of undesirability. Similarly, in the drugs policies, integral to setting up drugs as an endemic problem was its attachment to issues that feed off public imaginaries of fear. For example, drug taking is a problem '...because of drug related criminal activity and the fear that this causes' (Home Office, 1995: 37). This was developed in later texts to suggest that 'illegal drugs bring with them a range of problems and are a major issue of public concern' (Home Office, 2008: 8). 
The creation of a social problem always carries an inherent assumption of an alternative. Lianos and Douglas (2000) highlight that the promotion of particular social structures encourages a co-constitutive relationship between easily identifiable social harms and individuals who transgress normative boundaries. Homogenising both drug taking and, by extension, drug takers as socially problematic therefore invited an assumption of an alternative position. The user as social miscreant (often referred to as 'they' throughout the texts) was therefore always in direct opposition to the 'we' that represented both the government and the voice of the civilised norm:

Drugs remain a serious and complex problem that we - along with all modern societies - must face (Home Office, 2008: 4).

[Drug taking] limits the ability to work, to parent and to function effectively in society (Home Office 2008: 27, emphasis added).

The voices of social citizenship invoked here clearly build on narratives that construct the 'underclasses' as a disconnected part of the economic circuit. The result is a process of social marginalisation whereby such individuals are created as suffering from a moral deficit and lacking compared to 'us' (Young, 2000). As demonstrated in the Home Office excerpt above, fundamental to this was the hailing of a normative individual as able to function, both socially and economically. The role of the economically productive individual thus emerged as a key aspirational device: an individual who contributed to society through labour participation, but who also did not 'drain' resources creating crime or health-related burdens. By contrast the problematic worker emerged through their drug taking: 
Poor performance in school and at work are two consequences of drug misuse that produce unquantifiable costs in waste and inefficiency (Home Office, 1995: 38).

The direct cost of tackling drug misuse is also borne by many private organisations such as businesses, charities, and the voluntary sector generally (Home Office, 1995: $51)$.

The exclusivity of a socially and economically productive individual provided a norm that systematically marginalised others from becoming economically - and therefore morally viable citizens. Simultaneously, drug use was positioned as incompatible with full and efficient labour participation as seen in the 2010 Home Office drug strategy. This incompatibility was ensconced in statements such as 'drug and alcohol dependence is a key cause of inter-generational poverty and worklessness' (Home Office, 2010: 23). In doing so, the business community were located as key stakeholders within a prohibitive strategy through being positioned as directly affected by the negative consequences of drug users. Economic losses further justified a prohibitive stance in and of themselves. Consequently, 'work' moved from a discrete activity to a morally-loaded concept that both informs and is informed by images of socially dysfunctional drug use.

\section{The Employable Citizen as in Control and Autonomous}

The slippage between drugs 'use' and 'misuse' in the texts provided little discursive space for drug use to be deemed moderate or mediated, and thus situated those who consume as defacto deviants. This reduced the drug-taker's identity to the sum of their deviant behaviour, where individuals' behaviour was characterised solely by an irreversible loss of control. This was set up in the texts against traditional conceptions of the homo economicus employee who is 
able to behave and act rationally while pursuing maximum economic welfare. In this context, addiction must be the inevitable outcome of drug taking. For example, drugs produce 'chronic health problems that destroys lives' (Home Office, 2008: 8), and 'they [drug takers] are often addicted to heroin and/or crack/cocaine' (Home Office, 2002: 53). This assumption of harm and loss of control was invariably correlated with economic loss. The CMI guide to drugs in the workplace stated that:

Drug and alcohol misuse cannot only destroy the individual concerned, but can also have an extremely detrimental effect on the wider workforce, clients and customers and the organisation's performance (CMI, 2010: 1).

Other texts rested upon a 'set of practices that facilitate the governing of individuals from a distance...[and] as individualised and active subjects responsible for enhancing their own well-being' (Larner 2000: 6). Policies reproduced images of drug-taking individuals as definitively capable of not only harming themselves but also their immediate environments and society (Stevens et al., 2007). Consequently drug takers are simultaneously located in a space where responsibility for consumption lies with themselves, while positioned as individuals who cannot be relied upon because of a predicated disposition due to their consumption. Techniques such as strong contrast structures helped to present drug takers as marginal and thus requiring regulation. In many senses this echoes Gordon's (1994) suggestion that prohibition laws are predominantly aimed at the under - and dangerous classes. Just as Donoghue (2008: 345) suggests, particular characteristics may allow for the classification of 'risk groups'. This framing of drugs users as lacking control provided space for an interventionist stance: 
The government encourages employers to establish policies to deal with the issues surrounding drugs in the workplace... [The] damaging effects which drug misuse can have on health and work performance [mean there are] benefits of having agreed company-wide arrangements, which will help in the management and prevention of the problem (Home Office, 1995: 48).

As well as improving safety, tackling drug abuse - or preventing it in the first place [drug testing] also brings other business benefits, such as maintaining productivity levels and avoiding days being lost to business (Business Link, 2011: 5).

Texts relied on a progression from presenting objectivised definitions of drug-taking risks, towards defining instrumental modes of legitimate organisational control that could be actualised by organisations. Key to this shift was the promotion of a 'dangerization' thesis (Lianos and Douglas, 2000): a view of the world as a place of menace that requires a continual assessment (and the subsequent intervention) of threats. Subsequently, the drug taker was rendered impotent of self-control, with different bodies subsequently called upon to act via appealing to a moral duty. For example, the Home Office (1998) drug strategy focused on reducing crime connected to drug taking. In this and later strategies drug takers were metonymically linked with 'problems' and surrounded by lexical choices including 'waste', 'inefficiency' and 'underachievement' (Home Office, 1995; 1998; 2008). This was particularly the case for organisations, who were afforded a position that enables them to preempt possible organisational problems. Such legitimisation rested on a fundamental tenet of risk - the ability to act on the potential or possible threat, rather than an actuality through the presentation of 'defensive battles' (Beck et al., 1994: 45). This enabled texts to provide 
guidance for management to pre-emptively deal with drug-related concerns at work, suggesting that:

It is good practice to have a policy even if you do not find any evidence of current drug misuse. A policy which is in place will enable you to deal with any future problems which may arise (HSE, 2004: 8).

This interventionist stance echoes current modes of employee surveillance whereby increasing employee monitoring is legitimised through an assumption that outcomes lead to a 'safer' workplace for all, meaning that surveillance becomes 'first, a necessity, and second, a normal, taken-for-granted element of working life' (Ball, 2010: 89). However, within policy narratives, this worked alongside a causal justification between the dangers of drugs and the advantages of drugs management encased within a business case logic using (often vague) reasoning and values surrounding productivity alongside a sentiment of moral duty in order to legitimise a particular world view. For example, there was no attribution of work-related practices as resulting from, or contributing towards, drug use. This may include work intensification, work-related stress or 'after hours' business-related socialising, even though anecdotally these are instances where drug taking may overlap with the experience of work.

\section{The Employable Citizen as Redemptive}

The employable citizen also formed a key part in framing work as redemptive or part of a rehabilitative discourse. The 2008 strategy focussed repeatedly on the need to 'focus more upon treatment... reintegrate into society... [and] get[ing] back to work' (Home Office 2008: 4). A common feature was to present work as affording stability - either by providing a structure, or introducing a level of 'normality' - to individuals' lives that would otherwise be 
unorganised and chaotic. For example, the UK Drug Policy Commission (2008: 15), a subsidiary contributing to government policy, presents the challenges of getting drug users into employment whilst consistently returning to the idea that 'in general, work has positive benefits for an individual's health and well-being, bringing social and economic advantages to the employee and their families'.

Situating economic participation in this way required a move from wider social accountability towards individual responsibility. This was in part achieved through situating control over consumption at the locus of the individual, rather than ascribed to broader social or economic circumstances. Texts departed from traditional framings of drug takers as victims (cf. Harding, 1998), and instead placed drug-taking subjects as always able to access support and resources:

This government will work with, and offer every opportunity to those people who face up to the problems caused by their dependence on drugs or alcohol, and who wish to take steps to address them (Home Office, 2010: 18).

Here there was a lack of any contextual sensitivity to the situated nature of drug taking as often located within particular socio-economic milieu. In ignoring this dimension, economic participation could become a democratising feature, a way of redeeming oneself or working towards a sustainable and viable subject position as a 'citizen'. Echoing Rose (2000), work ethic within these policies becomes an integral part of neoliberalism, implying those initially excluded have the chance to become a member of a moral community through their labour. In doing so, the complex correlations between unemployment and socio-economic conditions of structures of inequality are silenced in favour of positioning drug use as moderating labour market participation. 
Avenues of redemption via work are key to the moral narratives surrounding drug taking (Maruna, 2001: 117), but also upheld principles of civilisation, specifically surrounding compassion and forgiveness (Powell, 2007). This provided a strong social-moral plot throughout the policy texts. Creating a stigmatised subject position therefore required a compensatory mechanism that was invoked through the idea of work as providing a 'second chance' to drug users. The employable citizen became aspirational: a position that could mitigate both drug-taking consequences on individuals' lives, and provide a sense of self and security (implied as lacking in drug users' lives). This was acute in the virtues attributed to economic participation:

Employment can help those in treatment to increase their 'recovery capital', for instance, by improving self-esteem and self-confidence (UK Drug Policy Commission, 2008: 16).

The government similarly suggested that employment helps 'recovering drug users find and sustain jobs - a key way of returning to a more stable and constructive life' (Home Office 2002: 42). Throughout the texts, the employable citizen as a redemptive position became an antidote for drug-related behaviours. Employment was a means through which a 'return' to a healthier, productive and normalised state could be achieved. Yet in presenting work as a safe space that enables drug takers to reintegrate into society, such strategies sanitise both work and the workplace as a safe place, ignoring the precarities of labour including stress, accidents and employment insecurity. This sanitising also presented the workplace as a cleansing environment that is free from taint, and work as something positively influencing individuals' behaviour, including their consumption choices, mirroring ideas surrounding the convergence and commodification of worker identities (c.f. Land and Taylor, 2010). In fore 
fronting the social function of work, economic participation was therefore presented as having a capacity to transform an individual's well-being, as well as aid a recovery from drug use.

\section{Discussion and Conclusions}

This study identified the concept of the employable citizen as the connective discursive subject that shapes current narratives surrounding drug taking and economic participation. Specifically, it shows how the employable citizen ideologically configures illegal drug takers as unproductive, untrustworthy and out of control, built on a reliance of apocalyptic potentialities and harm to the economic balance of society. In this sense drug taking can be represented solely as a threat and danger to organisational health. This negates concepts of enjoyment and pleasure that form part of the experience of drug consumption, as well as preventing a reflection on the diversity of experiences associated with different forms of intoxication (Blackman, 2007). A clear ontological tension ensues, whereby individuals are simultaneously denied any credence in being able to participate in drug consumption as sentient subjective agents, and yet are ascribed an ability and self-responsibility to make themselves employable citizens in the form advocated within the texts.

Consequently, it becomes impossible to reconcile or uphold the position of an employed drug taker, or at least for such a position to be recognised institutionally. However, while this presents a rather myopic view of drug consumption and employment, the popularity of such a nihilistic connection between economic participation and drugs is far from exclusive to our study. Although we only focus on the UK context, a country that has a particular cultural and political landscape surrounding drug taking and legislation (see Blackman, 2004), comparable patterns of zero-tolerance drug-taking policies exist elsewhere, such as in Sweden and Norway, as well as increasing modes of drug prohibition being 
prevalent throughout other Western industrialised societies (Pratt, 2008). In many cases, this feeds off growing social commentaries surrounding a youth 'underclass' that has been aligned with problematic drug cultures. These have subsequently encouraged a 'new authoritarianism within youth policy' (Blackman, 1997; Jeffs, 1997: 165); an authoritarianism that in turn legitimises more interventionalist drugs policy. It may be that similar discursive processes permeate 'drugs talk' in these countries, closing down any space for a diversity of discussions surrounding the socio-cultural importance of drugs, therefore preventing innovative strategies that recognise or engage with a multiplicity of drug consumption behaviours.

Our findings not only demonstrate the systematic reduction of consequences and behaviours surrounding drug taking, but show how the construction of an employable citizen allows the mobilisation of what Yeomans (2011: 41) calls a 'moral regulation' of substance use that reproduces the prerogative of sovereign bodies to act. Yet it also justifies the increasing regulation of individuals by powerful bodies, for example, through workplace drug testing. This limits the impact of evidence-based studies of drug taking by creating totalising and impermeable moral boundaries which privilege various actors' interests. Moreover, it promotes the extent to which individuals are organisationally 'owned', assuming 'the right of organisations to probe the bodies of workers and invoke private aspects of the self into management processes' (Ball, 2010: 92). This is particularly the case when drug-testing technologies pick up on consumption that has occurred hours, weeks or even months outside formally contracted labour.

Methodologically, our study highlights written documents' potential to present a series of recommendations through a range of authorities. Here the efficacy of texts to serve political discursive regimes is clear. Potentially they transform and influence organisational practice by simultaneously framing public problems and defining the boundaries of responses 
to these problems, thus acting as self-referential points to justify intervention. The logics identified in our analysis suggest that the dominance of an employable citizen subject position may allow organisations to pre-emptively manage 'the drugs problem' but also enable them to do so as part of the wider moral economy of drug taking. It is therefore unsurprising that we already see that organisational technologies frame interventionist practices - from drug testing to the surveillance of employees' social media activity - as aiding the management of a 'risky other' (Lyon, 2005). The lack of quantitative evidence is important in legitimising this reaction since 'individuals, organisations and societies have no choice but to organise in the face of uncertainty, to act "as if" they know the risks they face' (Power, 2004: 59).

While we are neither condoning nor condemning the consumption of any substance, the narrow conception of drug taking constructed and reproduced through the constitution of the employable citizen may have broader consequences. Of particular note is the 'whitecollaring' promotion of work where, despite many being employed in precarious and casualised forms of labour, contemporary images of work encourage an increasingly exclusive focus on professionalised modes of employment. This not only marginalises the importance of larger structural or economic inequalities and labour market conditions, as Brown and Hesketh (2004: 56-57) suggest, but also produces a narrow and sanitised conception of what 'work' is or should be. Just as Gordon (1994: 122) demonstrates how US prohibition law 'contain(s) the social consequences of structural instability', our work provides a account of how the reproduction of ideas surrounding drug takers produces a wider outcasting and differentiation of an 'underclass' (Jones, 2012; Skeggs and Loveday, 2012). The images of a steady fixed job and what constitutes 'valuable' work as projected in the texts are highly normative and may marginalise work that does not fit into a tightly constrained expectation of full-time paid employment. Moreover, it may not be a realistic 
presentation of the types of work that are available to those with particular cultural or socioeconomic resources. We suggest further work is therefore required to explore how these labour assumptions embedded in the employable citizen concept operate alongside other cultural apparatus in different social and occupational arenas.

\section{References}

ACMD (2013) Ketamine: A Review of Use and Harm. Available at:

https://www.gov.uk/government/uploads/system/uploads/attachment_data/file/264677/ACM

D_ketamine_report_dec13.pdf(Accessed 15 March 2014).

Ball K (2010) Workplace Surveillance: An Overview. Labor History 51 (1): 87-106.

Bancroft A (2009) Drugs, Intoxication \& Society. Cambridge: Polity Press.

Beck U (1992) Risk Society: Towards a New Modernity. London: Sage.

Beck U, Giddens A and Lash S (1994) Reflexive Modernization: Politics, Tradition and Aesthetics in the Modern Social Order. California: Stanford University Press.

Becker H (1953) Becoming a Marihuana User. The American Journal of Sociology 59 (3): $235-242$.

Blackman S (1997) 'Destructing a Giro': A Critical and Ethnographic Study of the Youth 'Underclass'. In: R MacDonald (ed) Youth, the 'Underclass' and Social Exclusion. Oxon: Routledge, pp. 113-129.

Blackman S (2004) "Chilling Out”: The Cultural Politics of Substance Consumption, Youth and Drug Policy. Maidenhead: Open University Press.

Blackman S (2007) 'See Emily Play': Youth Culture, Recreational Drug Use and Normalisation. In: Simpson M, Shildrick T and Robert Macdonald (eds) Drugs in Britain; Supply, Consumption and Control. Basingstoke: Palgrave Macmillan, pp. 3959. 
Brewis J, Sanderson C and Wray-Bliss E (2006) The Normalisation of 'Excessive' Workforce Drug Testing? TAMARA: Journal of Critical Postmodern Organization Science 5 (1-2): 39-53.

Brown P and Hesketh A (2004) The Mismanagement of Talent: Employability and Jobs in the Knowledge Economy. New York: Oxford University Press.

Bunton B (2001) Knowledge, Embodiment and Neo-liberal Drug Policy. Journal of Contemporary Drug Problems 28 (2): 221-244.

Candlin C and Maley Y (1997) Intertextuality and Interdiscursivity in the Discourse of Alternative Dispute Resolution. In: Gunnarsson B, Linnel P and Nordberg B (eds) The Construction of Professional Discourse. London: Longman, pp. 201-222.

Clarke J, Coll K, Dagnino E and Neveu C (2014) Disputing Citizenship. Bristol: Polity Press. Collin M (1997) Altered State: The Story of Ecstasy Culture and Acid House. London: Serpent's Tail.

Donoghue J (2008) Antisocial Behaviour Orders (ASBOs) in Britain: Contextualizing Risk and Reflexive Modernization. Sociology 42 (2): 337-355.

DWP (2010) Universal Credit: Welfare that Works. London: DWP.

Fleming P and Sturdy A (2009) "Just be Yourself"; Towards Neo-normative Control in Organisations? Employee Relations 31 (6): 569-583.

Foster J (2000) Social Exclusion, Crime and Drugs. Drugs: Education, Prevention and Policy 7 (4): 317-330.

Fujiwara D and Campbell R (2011) Valuation Techniques for Social Cost-Benefit Analysis. London: DWP.

Gazier B (1999) Employability: Concepts and Policies. Berlin: European Employment Observatory.

Goode E and Ben-Yehuda N (2009) Moral Panics; The Social Construction of Deviance. 
Chichester: Wiley-Blackwell.

Gordon D (1994) Return of the Dangerous Classes: Drug Prohibition and Policy Politics. New York: W.W. Norton \& Co.

Greely H, Sahakian B, Harris J, Kessier R, Gazzaniga M, Campbell P, and Farah M (2008) Towards Responsible Use of Cognitive-Enhancing Drugs by the Healthy. Nature 456 (1): 702-705.

Haines-Saah R, Johnson J, Repta R, Ostry A, Young M, Shoveller J, Ratner P (2014) The Privileged Normalization of Marijuana Use-An Analysis of Canadian Newspaper Reporting, 1997-2007. Critical Public Health 24 (1): 47-61.

Harding G (1998) Pathologising the Soul: The Construction of a 19th Century Analysis of Opiate Addiction. In: Coomber R (eds) The Control of Drugs and Drug Users; Reason or Reaction? Amsterdam: Harwood, pp. 1-13.

HM Government (2010) The Coalition: Our Programme for Government. London: HMSO. Home Office (1914) Defence of the Realm Act 1914. London: HMSO.

Hurenkamp M, Tonkens E and Duyvebdak J (2012) Crafting Citizenship: Negotiating Tensions in Modern Society. London: Palgrave.

IIDTW (2004) Drug Testing in the Workplace: The Report of the Independent Inquiry into Drug Testing at Work. Available at: http://www.jrf.org.uk/node/1183. (Accessed 7 October 2013).

Jeffs T (2007) Changing Their Ways: Youth Work and 'Underclass' Theory. In: R MacDonald (ed) Youth, the 'Underclass' and Social Exclusion. Oxon: Routledge, pp. $153-167$.

Johnson R (2007) Desperate Measures. People Management 13 (19): 32-37.

Jones O (2012) Chavs: The Demonization of the Working Class. London: Verso.

Labour Party (1997) New Labour: Because Britain Deserves Better. London: Labour Party. 
Land C and Taylor S (2010) Surf's Up: Work, Life, Balance and Brand in a New Age Capitalist Organization. Sociology 44 (3): 395-413.

Larner W (2000) Neo-Liberalism: Policy, Ideology, Governmentality. Studies in Political Economy 63 (1): 5-21.

Lianos M and Douglas M (2000) Dangerization and the End of Deviance. British Journal of Criminology 40 (2): 261-278.

Lyon D (2005) Surveillance Society: Monitoring Everyday Life. Buckingham: Open University Press.

McGregor S (2001) Neoliberalism and Health Care. International Journal of Consumer Studies 25 (2): 82-89.

Magoon E (1849) Proverbs for the People: Or, Illustrations of Practical Godliness Drawn from the Book of Wisdom. Boston: J.D. Flagg and W.H. Wardwell.

Maruna S (2001) Making Good: How Ex-Convicts Reform and Rebuild their Lives. Washington: American Psychological Association.

Nordenmark M and Strandh M (1999) Towards a Sociological Understanding of Mental Well-Being Among the Unemployed: The Role of Economic and Psychosocial Factors. Sociology 33 (3): 577-597.

Nutt D (2009) Equasy: An Overlooked Addiction with Implications for the Current Debate on Drugs Harms. Journal of Psychopharmacology 23 (1): 3-5.

O'Malley P and Valverde M (2004) Pleasure, Freedom and Drugs: the Uses of 'Pleasure' in Liberal Governance of Drug and Alcohol Consumption. Sociology 38 (1): 25-42.

Overbeek H (2003) Globalisation, Neo-liberalism and the Employment Question. Available at: http://bdi.mfa.government.bg/info/Module\%2009\%20\%20Ikonomicheska\%20diplomacia/dopalnitelna\%20literatura/wpps012003.pdf. (Accessed 7 October 2013). 
Parker H, Williams L and Aldridge J (2002) The Normalization of 'Sensible' Recreational Drug Use: Further Evidence from the North West England Longitudinal Study. Sociology 36 (4): 941-964.

Parker H, Aldridge J, Measham F and Williams L (2011) Illegal Leisure Revisited: Changing Patterns of Alcohol and Drug Use in Adolescents and Young Adults. London: Routledge.

Pennay A and Moore D (2010) Exploring the Micro-politics of Normalisation: Narratives of Pleasure, Self-control and Desire in a Sample of Young Australian 'Party Drug' Users. Addiction Research \& Theory 18 (5): 557-571.

Plant S (1999) Writing on Drugs. London: Faber and Faber.

Powell F (2007) The Politics of Civil Society; Neoliberalism or Social Left? Bristol: The Policy Press.

Power M (2004) The Risk Management of Everything: Rethinking the Politics of Uncertainty. London: Demos.

Pratt J (2008) Scandinavian Exceptionalism in an Era of Penal Excess; Part 1: The Nature and Roots of Scandinavian Exceptionalism. British Journal of Criminology 48 (2): 119-137.

Pryce S (2012) Fixing Drugs; The Politics of Drug Prohibition. Basingstoke: Palgrave Macmillan.

Robertson I and Cooper C (2011) Well-being: Productivity and Happiness at Work. Basingstoke: Palgrave Macmillan.

Rose N (2000) Community, Citizenship and the Third Way. American Behavioural Scientist 43 (9): 1395-1411.

Roth L (2010) The Moral Construction of Risk. In: Hitlin S and Vaisey S (eds) Handbook of the Sociology of Morality. London: Springer, pp. 469-485. 
Sanders B (2005) In the Club: Ecstasy Use and Supply in a London Nightclub. Sociology 39 (2): $241-258$.

Seddon T (2006) Drugs, Crime and Social Exclusion; Social Context and Social Theory in British Drugs-Crime Research. British Journal of Criminology 46 (4): 680-703.

Shiner M and Newburn T (1997) Definitely, Maybe Not: The Normalisation of Recreational Drug Use Amongst Young People. Sociology 31 (3): 511-529.

Skeggs B and Loveday V (2012) Struggles for Value: Value Practices, Injustice, Judgment, Affect and the Idea of Class. The British Journal of Sociology 63 (3): 472-490.

Stevenson N (2014) The Socialist Blues? Citizenship, Class and Civil Society. The Sociological Review 62 (1): 189-205.

Tuomi K, Ilmarinen J, Jahkola A, Katajarinne L and Tulkki A (1998) Work Ability Index. Report, Helsinki, Finland, December.

Turner B (2001) The Erosion of Citizenship. British Journal of Sociology 52 (2): 189-209.

Waddington I and Smith A (2009) An Introduction to Drugs in Sport: Addicted to Winning? Oxon: Taylor \& Francis.

Walker C (2011) "Responsibilizing” A Healthy Britain: Personal Debt, Employment and Welfare. International Journal of Health Services 41 (3): 525-538.

Weber M (2001) [1930] The Protestant Ethic and the Spirit of Capitalism. Abingdon: Routledge.

Wodak R, de Cillia R, Reisigl M and Liebhart K (2009) The Discursive Construction of National Identity. Edinburgh: Edinburgh University Press.

Workability Europe (2012) Inclusion Experts - Championing the Right to Work for Europeans. Report, Brussels, Belgium, January.

Yeomans H (2011) What Did the British Temperance Movement Accomplish? Attitudes to Alcohol, the Law and Moral Regulation. Sociology 45 (1): 38-53. 
Young J (2000) The Vertigo of Late Modernity. London: Sage. 
TABLE 1: List of Documents Analysed

\begin{tabular}{|c|c|c|c|c|}
\hline Author & Date & Title & Stated objective & Pages \\
\hline Business Link & 2011 & $\begin{array}{l}\text { Smoking Policies, Drugs } \\
\text { and Alcohol Abuse. }\end{array}$ & $\begin{array}{l}\text { Identifies and deal with } \\
\text { 'problems' concening } \\
\text { smoking, drugs and alcohol. }\end{array}$ & 6 \\
\hline $\begin{array}{l}\text { Cabinet } \\
\text { Office }\end{array}$ & 1998 & $\begin{array}{l}\text { Tackling Drugs to Build a } \\
\text { Better Britain; United } \\
\text { Kingdom Anti-Drugs Co- } \\
\text { ordinator's Annual Report } \\
\text { 1998/99. }\end{array}$ & $\begin{array}{l}\text { Evaluates the progress of the } \\
\text { first government strategy on } \\
\text { drug taking prohibition. }\end{array}$ & 23 \\
\hline CIPD & 2007 & $\begin{array}{l}\text { Managing Drug and } \\
\text { Alcohol Misuse at Work: A } \\
\text { Guide for People } \\
\text { Management Professionals. }\end{array}$ & $\begin{array}{l}\text { Guide focussing on key issues } \\
\text { in managing employees who } \\
\text { misuse drugs and alcohol. }\end{array}$ & 43 \\
\hline CMI & 2002 & $\begin{array}{l}\text { Drugs and Alcohol in the } \\
\text { Workplace - Guidance for } \\
\text { Managers. }\end{array}$ & $\begin{array}{l}\text { Raises awareness of drugs } \\
\text { issues and provides policy } \\
\text { recommendations to produce a } \\
\text { support network. }\end{array}$ & 6 \\
\hline CMI & 2003 & $\begin{array}{l}\text { Managing the Effects of } \\
\text { Drugs and Alcohol in the } \\
\text { Workplace. }\end{array}$ & $\begin{array}{l}\text { Details the findings from a } \\
\text { survey of managers' attitudes } \\
\text { to drugs and alcohol at work. }\end{array}$ & 6 \\
\hline CMI & 2010 & $\begin{array}{l}\text { Best Practice: Drugs and } \\
\text { Alcohol in the Workplace; } \\
\text { Guidance for Managers. }\end{array}$ & $\begin{array}{l}\text { Raises awareness of drugs } \\
\text { issues and provides policy } \\
\text { recommendations to produce a } \\
\text { support network. }\end{array}$ & 3 \\
\hline Home Office & 1995 & $\begin{array}{l}\text { Tackling Drugs Together; } \\
\text { A Strategy for England. }\end{array}$ & $\begin{array}{l}\text { Focuses on reducing the } \\
\text { consequences of drug taking } \\
\text { on communities and increasing } \\
\text { public health. }\end{array}$ & 77 \\
\hline Home Office & 1998 & $\begin{array}{l}\text { Tackling Drugs to Build a } \\
\text { Better Britain. }\end{array}$ & $\begin{array}{l}\text { Focuses on creating a healthy } \\
\text { and confident society, free } \\
\text { from the harm caused by drug } \\
\text { misuse. }\end{array}$ & 116 \\
\hline Home Office & 2002 & Updated Drug Strategy. & $\begin{array}{l}\text { Focuses on harm reduction } \\
\text { surrounding drug use. }\end{array}$ & 82 \\
\hline Home Office & 2008 & $\begin{array}{l}\text { Drugs: Protecting Families } \\
\text { and Communities; The } \\
2008 \text { Drug Strategy. }\end{array}$ & $\begin{array}{l}\text { Proposes a strategy to reduce } \\
\text { the harms of drug taking. }\end{array}$ & 68 \\
\hline Home Office & 2010 & $\begin{array}{l}\text { Drug Strategy } 2010 \\
\text { Reducing Demand, } \\
\text { Restricting Supply, } \\
\text { Building Recovery: } \\
\text { Supporting People to Live a } \\
\text { Drug Free Life. }\end{array}$ & $\begin{array}{l}\text { Proposes a strategy to restrict } \\
\text { the demands for and supply of } \\
\text { drugs. }\end{array}$ & 26 \\
\hline HSE & 2004 & $\begin{array}{l}\text { Drug Misuse at Work; } A \\
\text { Guide for Employers. }\end{array}$ & $\begin{array}{l}\text { Guide for managers to deal } \\
\text { with drug-related 'problems' at } \\
\text { work. }\end{array}$ & 24 \\
\hline HSE & 2007 & $\begin{array}{l}\text { Don't Mix It; A Guide for } \\
\text { Employers on Alcohol at }\end{array}$ & $\begin{array}{l}\text { Provides a four-step approach } \\
\text { for employers for tackling }\end{array}$ & 12 \\
\hline
\end{tabular}




\begin{tabular}{|l|l|l|l|l|}
\hline & & Work. & problems related to alcohol. & \\
\hline UK Drug & 2008 & $\begin{array}{l}\text { Working Towards } \\
\text { Pecovery; Getting Problem } \\
\text { Commission }\end{array}$ & $\begin{array}{l}\text { Presents the challenges of } \\
\text { transitioning drug users into } \\
\text { Drug Users Into Jobs. }\end{array}$ & \\
employment. & \\
\hline
\end{tabular}

\section{Biographies}

Charlotte Smith is a Lecturer in Organisation Behaviour in the York Management School, University of York, UK. She recently completed her $\mathrm{PhD}$ at the University of Essex, exploring the intersections and experiences surrounding illegal drug taking and organizational life. Her current research interests include the cultural representations of drugs and work, and employees' legal and illegal drug taking in relation to performance enhancement and productivity.

Kathleen Riach is an Associate Professor of Management at Monash Business School, Monash University, Australia. Her research explores the embodied negotiation of identities in the everyday experiences of working life, with a particular focus on ageing and the role of the senses. Recent research has been published in internationally renowned journals such as Urban Studies, Human Relations and Organization Studies, as well as presented in National and International policy arenas including the United Nations. She is currently working on a multi-disciplinary study titled 'Women, Work and the Menopause'. 